\title{
MICROSTRUCTURE AND PHASE TRANSFORMATIONS IN DENTAL GOLD ALLOYS
}

\section{DETERMINATION OF A COHERENT PHASE DIAGRAM}

\author{
Katsubiro Yasuda \& Kunibiro Hisatsune \\ Department of Dental Materials Science \\ Nagasaki University School of Dentistry \\ Nagasaki, Japan
}

Electron microscopy has a lot to offer materials scientists in helping them to understand the dependence of mechanical and electrochemical properties on the microstructures resulting from phase transformations in dental alloys. A coherent phase diagram gives us effective information as an aid to developing improved dental alloys. This brief article describes the process of construction of a coherent phase diagram for the $\mathrm{Au}_{\mathrm{x}}-\left(\mathrm{Ag}_{0.24} \mathrm{Cu}_{0.76}\right)_{1-\mathrm{x}}$ section of the gold-copper-silver ternary system, which is the essential system of dental gold alloys, using conventional transmission electron microscopy coupled with selected area electron diffraction. 


\section{INTRODUCTION - WHY DO WE NEED a PHASE DIAGRAM?}

According to American Dental Association (ADA) Specification No. 5 and International Standard ISO 1562, dental gold alloys for casting are classified into four types, I, II, III and IV, by their gold and platinum metals content and their mechanical properties. Among other things, the Type IV alloys are designed to be age-hardenable by an appropriate heat treatment.

As is prescribed in ADA specification No.5, the Type IV alloys can be softened by quenching after being heated for $0.6 \mathrm{ks}\left(10 \mathrm{~min}\right.$.) at $973 \mathrm{~K}\left(700^{\circ} \mathrm{C}\right)$ at which temperature a single-phase solid solution is formed in the alloys. The quenching tends to suppress phase transformation by preventing diffusion of solute atoms in the crystal lattice. Subsequent hardening is achieved by slow cooling from $723 \mathrm{~K}\left(450^{\circ} \mathrm{C}\right)$ to $523 \mathrm{~K}\left(250^{\circ} \mathrm{C}\right)$ in $1.8 \mathrm{ks}(30 \mathrm{~min}$.) at a constant cooling rate, without referring to a critical temperature for phase transformation in each particular alloy. The hardening heat-treatment seems to be based on the fact that the critical temperature of the Type IV dental gold alloys usually exists between 723 and $523 \mathrm{~K}$. However, the actual critical temperature for phase transformation varies among the alloys, depending upon their composition.

Moreover, the type of phase transformation is different at each temperature in an alloy. Microstructures and mechanical properties are affected by the types and sequence of the phase transformations in the alloy.

For instance, Figure 1 represents a Time-Temperature-Transformation (T-T-T) diagram in the Au-49.7at.$\% \mathrm{Cu}-15.8 \mathrm{at} . \% \mathrm{Ag}$ alloy, as determined by X-ray and electron diffraction as well as transmission electron microscopy [1]. It is clear that the type of the phase transformation varies at temperatures above and below the critical temperature, $T_{c}$, a modulated structure induced by spinodal decomposition being formed in the initial stage of ageing throughout the temperature range. The modulated structure grows into a 'tweedlike' structure which is composed of $\alpha_{1}$ and $\alpha_{2}$ disordered phases, both fcc in structure, due to phase separation by further ageing above $T_{c}$.

While AuCu II ordering is formed from a copperrich portion in the modulated structure by ageing below $T_{c}$, the $\alpha_{1}, \alpha_{2}$ disordered and AuCuII long-period ordered phases are formed by prolonged ageing in the higher temperature range below $T_{c}$. The $\mathrm{Cu}_{3} \mathrm{Au}$ ordering is also induced by ageing in the lower temperature range below $T_{c}$, and the $\alpha_{2}$ disordered, $\mathrm{Cu}_{3-}$ $\mathrm{Au}$ and $\mathrm{AuCuII}$ ordered phases are also formed by lengthy ageing in this temperature range.

In Figure 1, thick solid lines with shading indicate the locus of the maximum hardness values determined by isothermal ageing. The dot-and-dash-line shows the critical temperature for AuCuII ordering in the alloy. The broken line represents the phase boundary between the region where the three phases AuCuII, $\alpha_{1}$ and $\alpha_{2}$ coexist and the $\mathrm{Cu}_{3} \mathrm{Au}-\mathrm{AuCuII}-\alpha_{2}$ three-phase region; it also shows the critical temperature for $\mathrm{Cu}_{3} \mathrm{Au}$ ordering.

Another broken line with arrows represents the cooling curve of the hardening treatment prescribed in ADA specification No. 5 (slow cooling from 723 to $523 \mathrm{~K}$ in $1.8 \mathrm{ks}$ at a constant cooling rate).

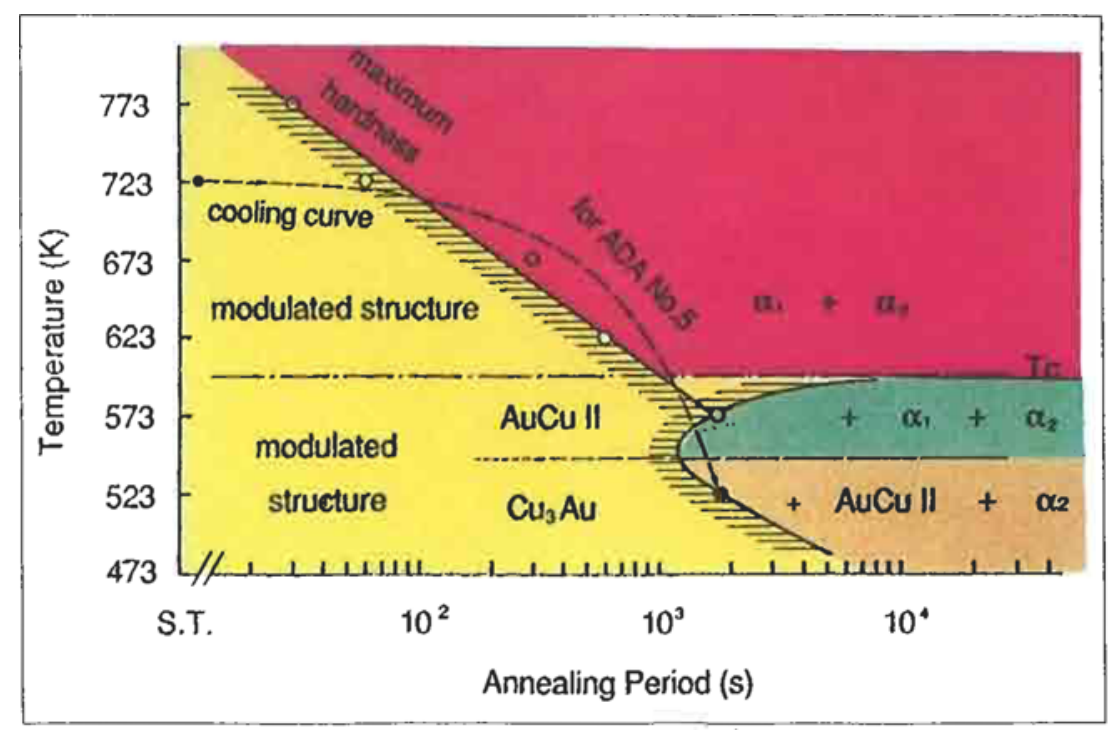

Figure 1

Time-Temperature-Transformation diagram of $\mathrm{Au}-49.7 \mathrm{at} . \% \mathrm{Cu}$ $15.8 \mathrm{at} . \% \mathrm{Ag}$ alloy and the cooling curve prescribed in ADA specification No.5 for dental gold casting alloys 
From Figure 1, it is clear that the sequence of phase transformations is a complex process depending upon ageing temperatures and times, even if the ageing is performed at a constant temperature, because the sequence of phase transformations in this alloy involves dual mechanisms of ordering and phase separation. Spinodal decomposition is also attributed to the age-hardening in the initial stage of
- predict what phases are in equilibrium for selected alloy compositions at required temperatures;

- determine the chemical composition of each phase;

- calculate a volumetric ratio of each phase that is formed in the alloy and

- predict phase transformations which give rise to changes in mechanical and electrochemical properties as well as biological characteristics.

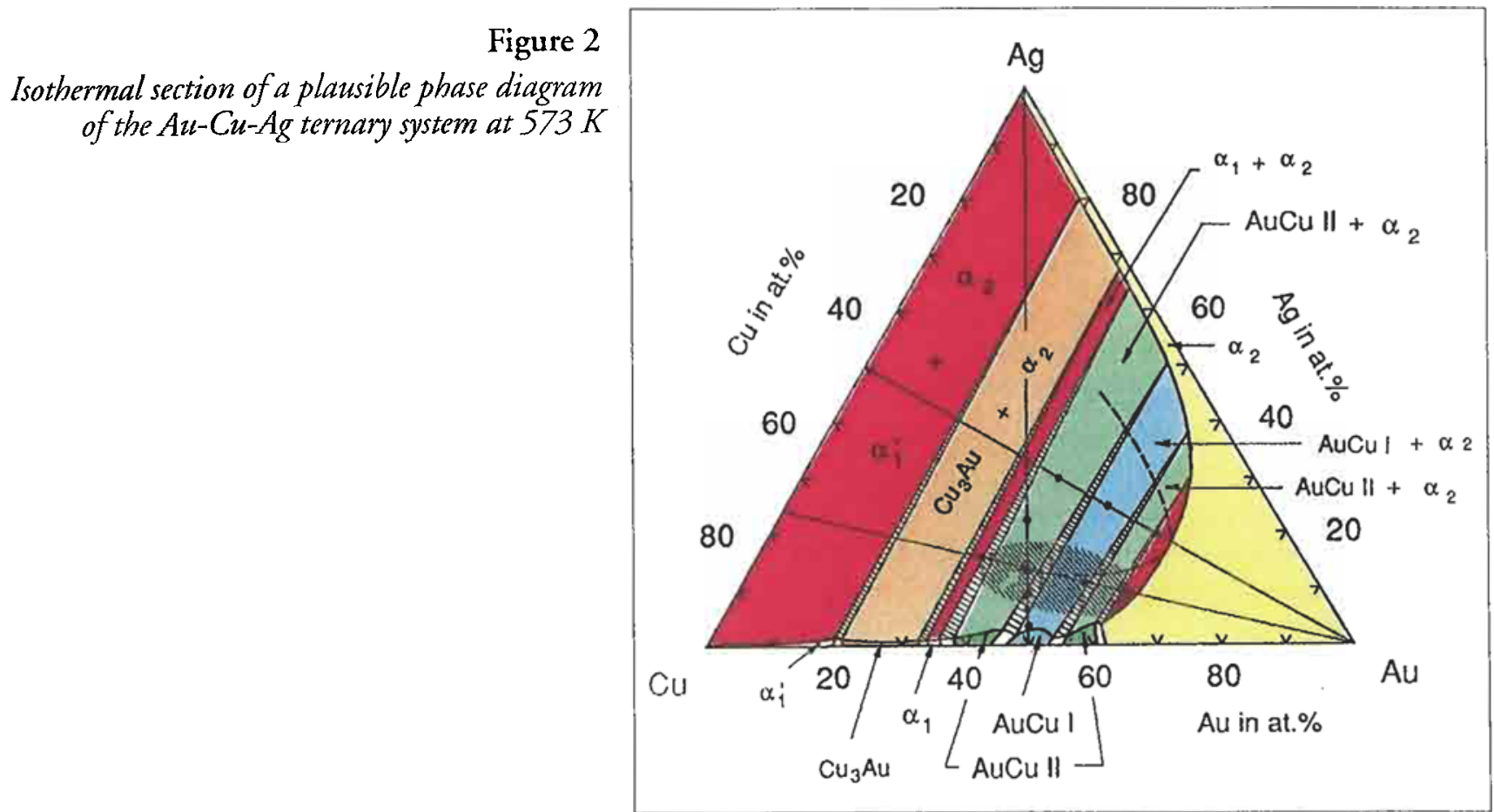

ageing in the alloy $[1,2]$. During slow cooling from 723 to $523 \mathrm{~K}$, the hardening occurs mainly by spinodal decomposition and to a lesser extent by AuCu II ordering. The spinodal decomposition, however, is thought to be an undesirable mechanism of agehardening for dental gold alloys, because brittleness will be caused by the formation of a modulated structure.

Thus, several questions arise from the heat-treatment method prescribed in ADA specification No. 5 as well as in the ISO specification for dental gold alloys. It is important, therefore, to precisely determine the critical temperature of phase transformations and to construct a phase diagram for each dental gold alloy. Generally, a phase diagram gives us effective information to enable us to:
Accordingly, the following research projects are being conducted by our laboratory in the Nagasaki University School of Dentistry:

- Construction of a coherent phase diagram for the $\mathrm{Au}-\mathrm{Cu}-\mathrm{Ag}$ ternary system.

- Phase transformations and the associated microstructural changes in $\mathrm{Au}-\mathrm{Cu}-\mathrm{Ag}$ ternary alloys.

- Age-hardening and the related phase transformations in $\mathrm{Au}-\mathrm{Cu}-\mathrm{Ag}$ ternary alloys and commercial dental gold alloys.

- Interfacial configurations induced by phase transformation in Au-Cu-Ag ternary alloys.

This review article attempts to explain how to determine the coherent phase diagram of a section in the $\mathrm{Au}-\mathrm{Cu}-\mathrm{Ag}$ ternary system on the basis of studies using electron microscopy. 


\section{CONSTRUCTION OF A COHERENT PHASE DIAGRAM OF THE $A u_{x}-\left(A_{0.24} C_{u_{0.76}}\right)_{1-x}$ SECTION IN THE Au-Cu-Ag TERNARY SYSTEM}

According to the hypothesis of Allen and Cahn [3], a coherent phase must be metastable and, in the presence of the incoherent phase, must be unstable; coherency strain must also be present in the coherent multi-phase structure, and dislocation must be visible at the interfaces with the incoherent phase to reduce coherency strain. Thus, it is thought that grain boundary products are equilibrium incoherent phases, while phases formed in the grain interior are metastable coherent phases. A coherent phase diagram, therefore, gives us more effective information to predict phase transformations related to age-hardening characteristics in an alloy system than an incoherent phase diagram.

As the first step of our systematic study, a coherent phase diagram of the $\mathrm{Au}_{\mathrm{x}}-\left(\mathrm{Ag}_{0.24} \mathrm{Cu}_{0.76}\right)_{1-\mathrm{x}} \mathrm{sec}-$ tion in the $\mathrm{Au}-\mathrm{Cu}-\mathrm{Ag}$ ternary system was examined

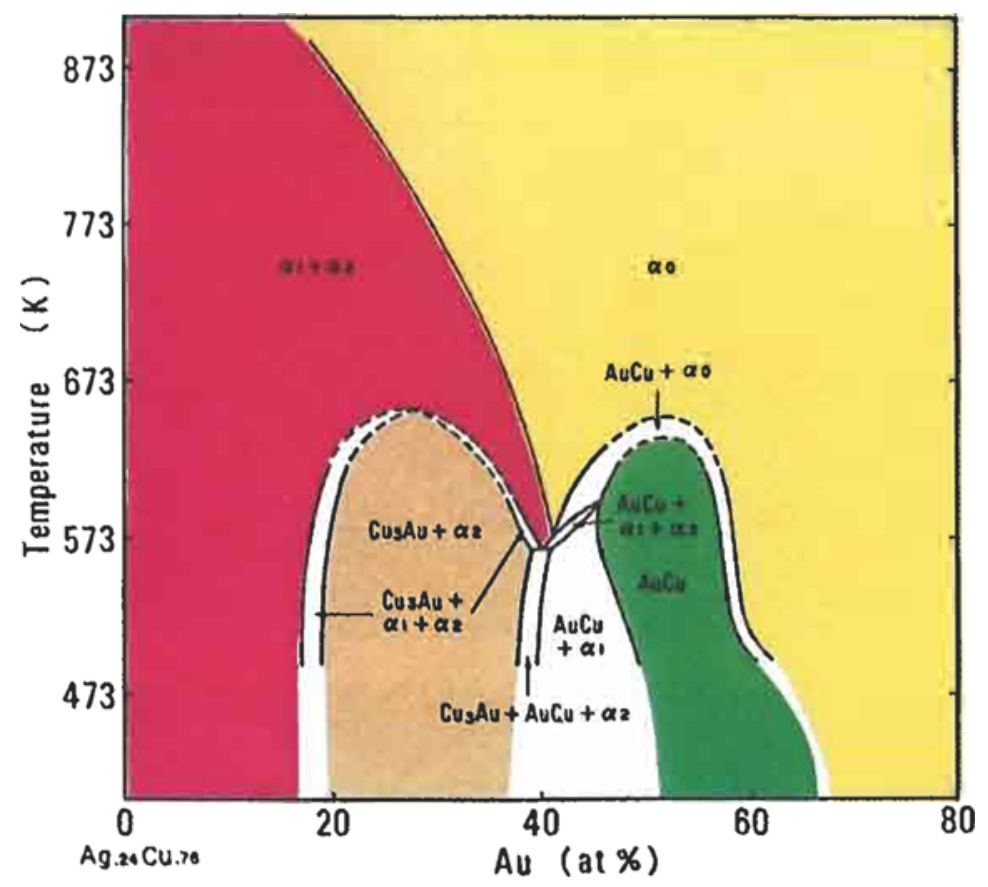

Figure 4

Theoretical coherent phase diagram of the $A u_{x}-(A g 0.24 C u 0.76)_{1-x}$ pseudobinary section in the $\mathrm{Au}-\mathrm{Cu}-\mathrm{Ag}$ ternary system

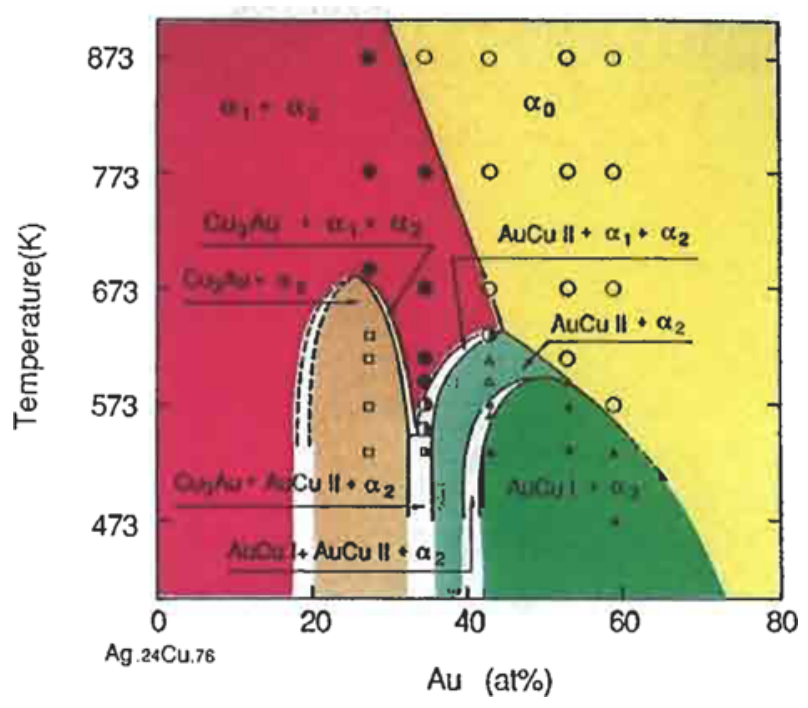

Figure 3

Experimental coherent phase diagram of the $A u_{x}-(\text { Ago.24Cu0.76) })_{1-x}$ pseudobinary section in the Au-Cu-Ag ternary system

by means of transmission electron microscopy (TEM) and selected area electron diffraction (SAED), since the compositions of most commercial dental gold alloys are in a region close to the section as seen in Figure 2.

The experimental result obtained is shown in Figure 3 [4]. A theoretical coherent phase diagram of the same vertical section in the $\mathrm{Au}-\mathrm{Cu}-\mathrm{Ag}$ ternary system is also represented in Figure 4, which is calculated using the cluster variation approximation by Yamauchi [5]. Although there are slight differences between the locations of the experimental and theoretical phase boundary lines, both coherent phase diagrams represent a two-phase region which was formed by phase separation, ordering regions of two types, i.e. $\mathrm{Cu}_{3} \mathrm{Au}$ and $\mathrm{AuCu}$ ordered phases, and coexisting regions associated with these two or three phases. In the theoretical coherent phase diagram, the longperiod superstructure of the AuCuII phase cannot be distinguished from the $\mathrm{AuCuI}$ tetragonal superstructure, because all the 
Table 1

Composition of the experimental alloys and their lattice parameters in solid solution

\begin{tabular}{|c|c|c|c|c|c|}
\hline \multirow{2}{*}{$\begin{array}{l}\text { Alloy } \\
\text { Speci- } \\
\text { mens }\end{array}$} & \multirow[b]{2}{*}{ Code } & \multicolumn{3}{|c|}{$\begin{array}{c}\text { Composition of alloy } \\
\text { (at.\%) }\end{array}$} & \multirow{2}{*}{$\begin{array}{l}\text { Lattice parameter of } \\
\text { solid solution }(\mathrm{nm})\end{array}$} \\
\hline & & $\mathrm{Au}$ & $\mathrm{Cu}$ & $\mathbf{A g}$ & \\
\hline a & $3 G$ & 48.5 & 48.5 & 3 & - \\
\hline b & $6 G$ & 46.9 & 47.5 & 5.6 & 0.3890 \\
\hline c & $9 G$ & 45.5 & 45.5 & 9 & - \\
\hline d & $16 \mathrm{~K}$ & 43.0 & 43.3 & 13.9 & 0.3903 \\
\hline e & $17 G$ & 36.2 & 41.4 & 22.4 & 0.3915 \\
\hline$f$ & $28 G$ & 33.4 & 35.5 & 31.1 & 0.3839 \\
\hline$g$ & $18 \mathrm{~K}$ & 53.1 & 35.6 & 11.3 & 0.3838 \\
\hline h & $14 K$ & 34.5 & 49.8 & 15.7 & 0.3875 \\
\hline i & $60 \mathrm{~A}$ & 60 & 20 & 20 & 0.4003 \\
\hline j & $50 \mathrm{~A}$ & 50 & 25 & 25 & 0.3986 \\
\hline k & $40 \mathrm{~A}$ & 40 & 30 & 30 & 0.3960 \\
\hline 1 & $19 \mathrm{~K}$ & 58.9 & 31.2 & 9.9 & 0.3957 \\
\hline $\mathrm{m}$ & $12 \mathrm{~K}$ & 27.4 & 55.2 & 17.4 & 0.3850 \\
\hline
\end{tabular}

possible compounds formed must be superstructures of the lattice of the parent disordered fcc phase on the basis of the cluster variation approximation [6]. Therefore, the AuCuII ordered phase region cannot be seen in the theoretical coherent phase diagram shown in Figure 4.

A cross-section of the ternary eutectoid isotherm is shown as a horizontal line in Figure 3. Although the eutectoid reaction is not confirmed by any experimental evidence, detailed examination of TEM mi- crostructures and SAED patterns clearly indicates the coexistence of $\mathrm{Cu}_{3} \mathrm{Au}$ and $\mathrm{AuCuII}$ ordered phases and a disordered $\alpha_{2}$ phase, as will be shown later. Moreover, the theoretical coherent phase diagram correctly predicts a eutectoid relationship between $\mathrm{Cu}_{3} \mathrm{Au}$ and $\mathrm{AuCu}$ ordered phases.

Consequently, it is shown that the experimental coherent phase diagram of the $\mathrm{Au}_{\mathrm{x}}-\left(\mathrm{Ag}_{0.24} \mathrm{Cu}_{0.76}\right)_{1-\mathrm{x}}$ pseudobinary system contains five distinguishable phase regions:
Figure 5

TEM bright-field images showing changes in microstructure of the $12 \mathrm{~K}$ alloy aged for various periods: (a) $0.06 \mathrm{ks}$, (b) $0.3 \mathrm{ks}$, (c) $1.0 \mathrm{ks}$, (d) $30 \mathrm{ks}$
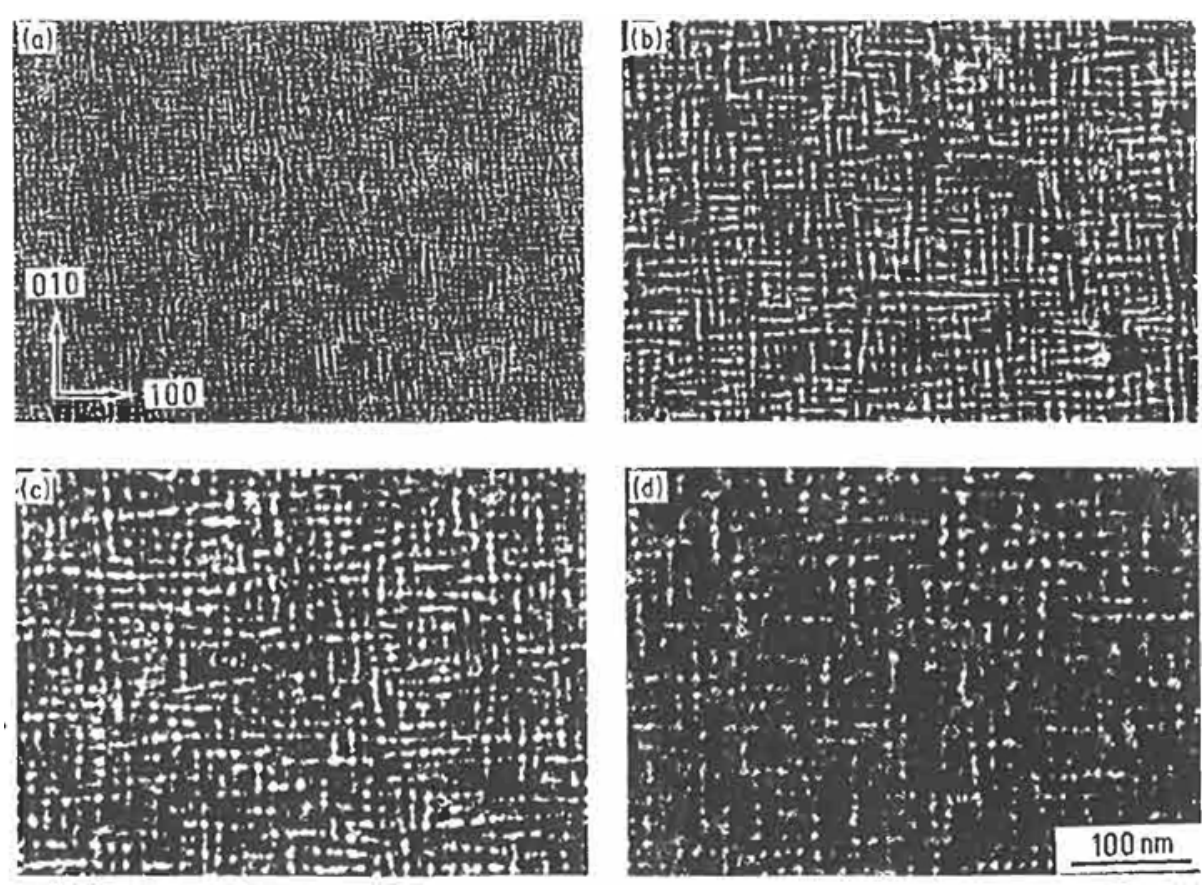
(1) a disordered solid solution region, $\alpha_{0}$ (fcc);

(2) a two-phase coexisting region, i.e. $\alpha_{1}$ (copper-rich fcc phase) $+\alpha_{2}$ (silver-rich fcc phase);

(3) regions of coexistence of a disordered phase and an ordered phase, i.e. $\alpha_{2}+\mathrm{Cu}_{3} \mathrm{Au}\left(\mathrm{Ll}_{2}\right), \alpha_{2}+\mathrm{Au}-$ $\mathrm{CuI}\left(\mathrm{Ll}_{0}\right)$;

(4) regions of coexistence of two disordered phases and an ordered phase, i.e. $\alpha_{1}+\alpha_{2}+\mathrm{Cu}_{3} \mathrm{Au}$ and $\alpha_{1}+\alpha_{2}$ + AuCuII and

(5) regions of coexistence of a disordered phase and two ordered phases, i.e. $\alpha_{2}+\mathrm{Cu}_{3} \mathrm{Au}+\mathrm{AuCuII}$ and $\alpha_{2}+\mathrm{AuCuI}+\mathrm{AuCuII}$.

The microstructure of these regions exhibits different features due to types of phase transformations which depend on the composition of the alloys, ageing temperatures and times. However, a similarity of microstructures was found, attributed to controlling mechanisms of phase transformations in the initial stage of ageing, i.e. the spinodal decomposition or nucleation and growth mechanism. For reference in the following sections, the codes and compositions of the specimen alloys are listed with their lattice parameters in solid solution in Table 1. fundamental diffraction reflection and equivalent positions during the initial stage of isothermal ageing at $613 \mathrm{~K}$. With the progress of ageing, the sidebands moved closer to the 200 fundamental reflections. These changes suggest the formation of a modulated structure resulting from spinodal decomposition. The effect of ageing times at $613 \mathrm{~K}$ on the modulated structure can be clearly seen in Figure 5, in which the average wavelength of the modulation increases with progress of ageing; it is approximately $6.7 \mathrm{~nm}$ and $13.7 \mathrm{~nm}$ in the specimens aged for 0.06 and $30 \mathrm{ks}$, respectively [7].

On ageing of the $12 \mathrm{~K}$ alloy for $10 \mathrm{ks}$ at $613 \mathrm{~K}$, superlattice reflections appeared in the SAED pattern at the positions of the 100,110 and equivalent positions though their intensity was extremely weak. With increasing ageing time, the superlattice reflections became clearly visible with increasing intensity.

An SAED pattern for the $12 \mathrm{~K}$ alloy aged at $613 \mathrm{~K}$ for $30 \mathrm{ks}$ and its schematic representation are shown in Figures $6 a$ and $6 b$, respectively. Appearance of the superlattice reflections at these positions suggests the

\section{PHASE TRANSFORMATIONS AND RELATED MICROSTRUCTURE IN $\mathrm{Au}_{\mathrm{x}}-\left(\mathrm{Ag}_{0.24} \mathrm{Cu}_{0.76}\right)_{1-\mathrm{x}}$ PSEUDOBINARY ALLOYS}

\section{Two-phase Region \\ of Coexisting $\mathrm{Cu}_{3} \mathrm{Au}$ and $\alpha_{2}$ Phases}

Figure 5 shows bright-field TEM micrographs of the $12 \mathrm{~K}$ alloy aged at $613 \mathrm{~K}$ for various times. The microstructures show that modulation occurs along $<100>_{\mathrm{fcc}} \mathrm{di}$ rections, since side-bands appeared in the $\mathrm{X}$-ray diffraction profile around the 200
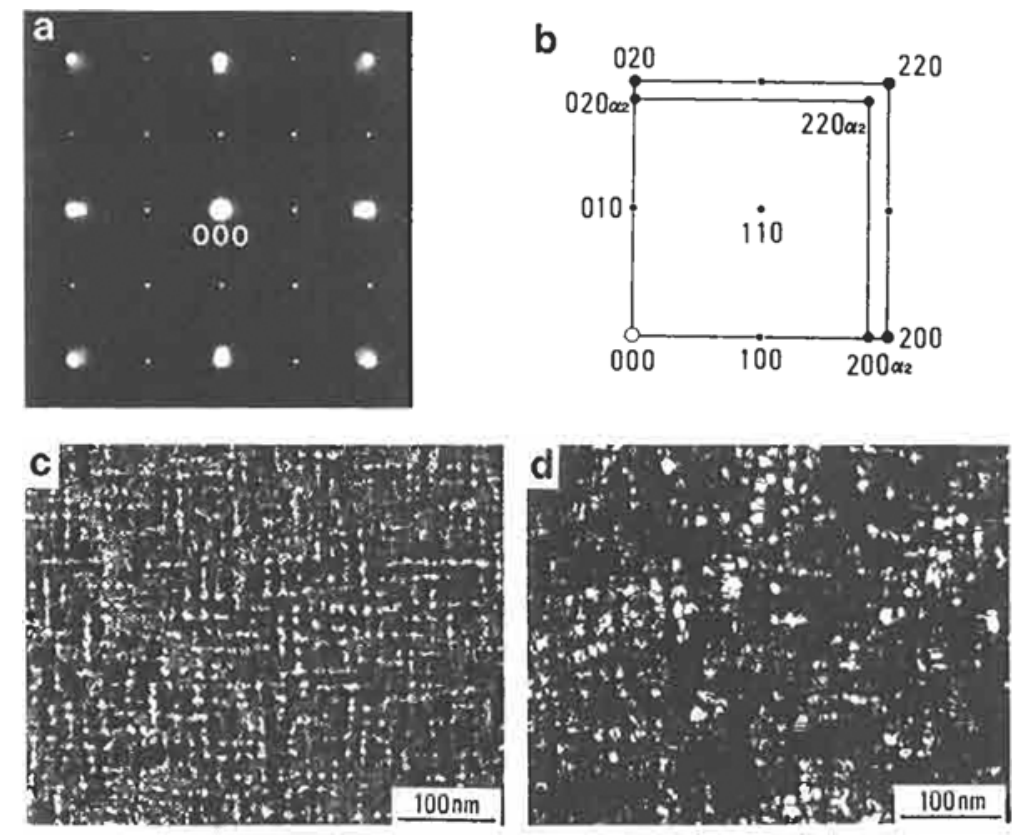

Figure 6

Electron diffraction pattern and TEM micrographs of the $12 \mathrm{~K}$ alloy aged at $613 \mathrm{~K}$ for $30 \mathrm{ks}$; (a) [001] SAED pattern,

(b) the schematic representation of (a), (c) bright-field image, (d) 110 dark-field image 

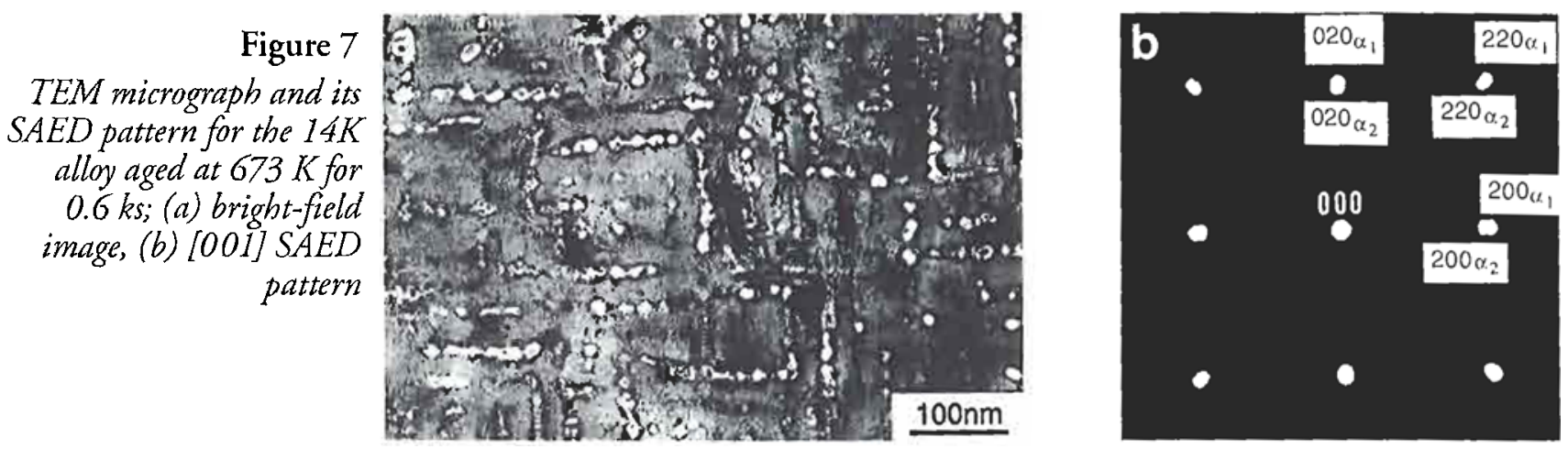

formation of an $\mathrm{L}_{2}$ type superlattice $\mathrm{Cu}_{3} \mathrm{Au}$. A disordered fcc phase, identified from its lattice parameter as the $\alpha_{2}$ phase, is observed accompanying the $\mathrm{Cu}_{3} \mathrm{Au}$ ordered phase in Figures $6 a$ and $6 b$.

Bright-field and dark-field images produced by using the 110 superlattice reflection are shown in Figures $6 \mathrm{c}$ and $6 \mathrm{~d}$, respectively. In the bright-field image, alternating black and white striations are observed running parallel to the $\langle 100\rangle$ directions and are arranged at right angles to one another. These striations suggest the formation of the modulated structure comprising the $\alpha_{2}$ phase and $\mathrm{Cu}_{3} \mathrm{Au}$ ordered phase [4].

\section{Two-phase Region of Coexisting $\alpha_{1}$ and $\alpha_{2}$ Phases}

Figures $7 \mathrm{a}$ and $7 \mathrm{~b}$ show a bright-field image and the corresponding SAED pattern for the $14 \mathrm{~K}$ alloy aged at $673 \mathrm{~K}$ for $0.6 \mathrm{ks}$. In the bright-field image, numerous precipitates are observed as bright bands parallel to the $\langle 100\rangle$ directions in the matrix. These precipitates are identified as the $\alpha_{2}$ phase and $\alpha_{1}$ matrix, both $f_{c c}$ in structure as is indicated by the SAED pattern shown in Figure $7 \mathrm{~b}$. The microstructure is somewhat similar to those shown in Figures 5 and 6, and seems to be developed from the modulated structure in-
TEM micrographs and $S A E D$ pattern for the $16 \mathrm{~K}$ alloy aged at $613 \mathrm{~K}$ for $10 \mathrm{ks}$; (a) and (b) the dark-field images produced using the $001 X$ and $110 Z$ superlattice reflections, respectively, (c) [001] SAED pattern,

(d) the schematic representation of $(c)$
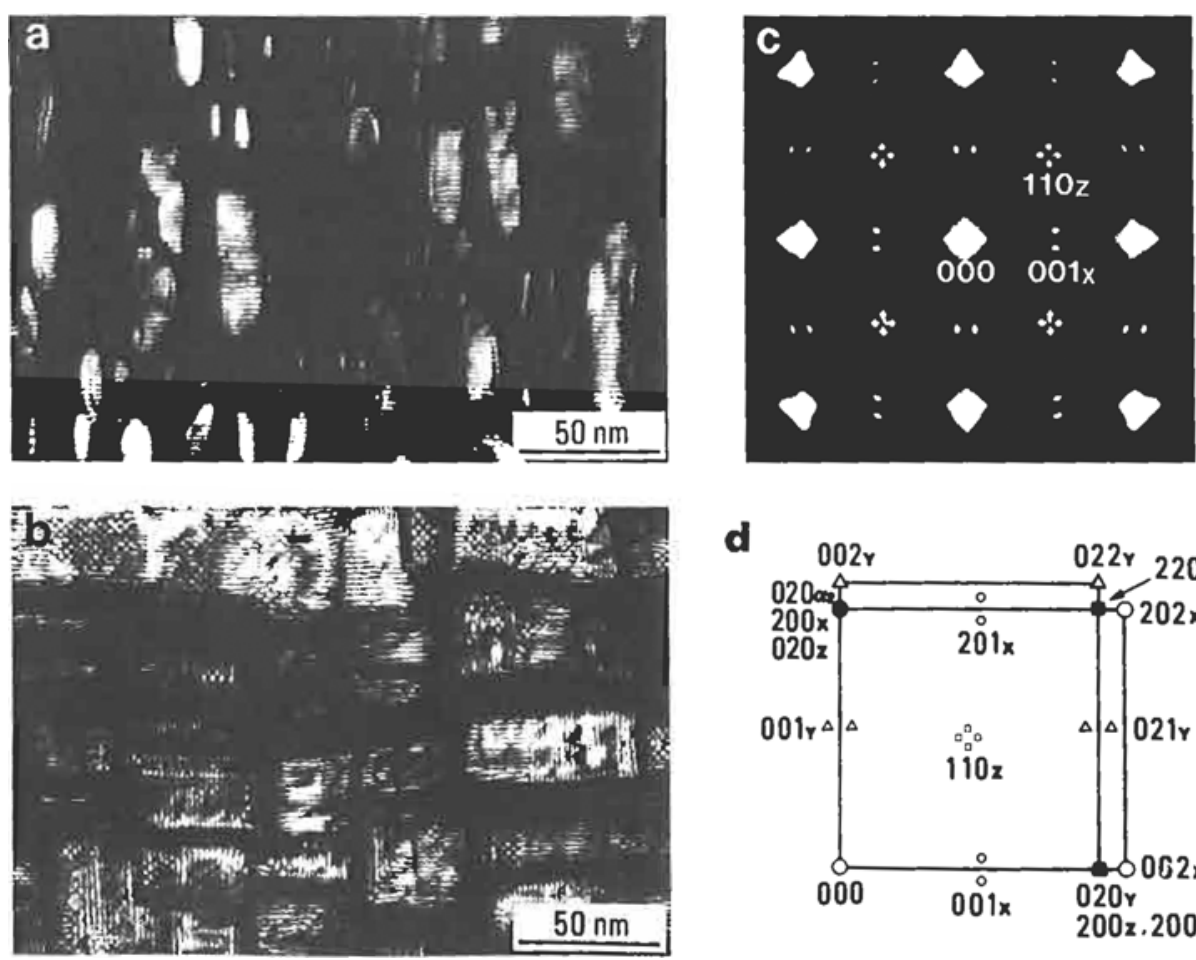

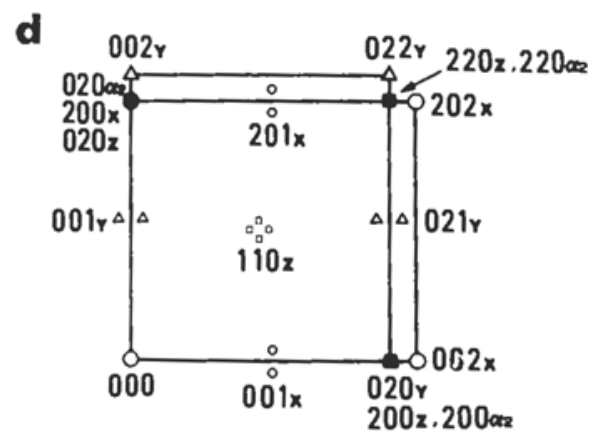


duced in the early stage of ageing. In fact, it has been reported that the modulated structure occurs by spinodal decomposition in the early stage of ageing at $673 \mathrm{~K}$ in the $14 \mathrm{~K}$ alloy [1]. Thus, it is understood that the microstructure which is constructed of bright bands of the $\alpha_{2}$ phase parallel to the $<100>$ directions in the matrix is developed from the modulated structure by further ageing.

At higher ageing temperature, however, the phase separation was generated by a nucleation and growth mechanism. A characteristic lamellar structure was also observed at the grain boundaries in the case of lengthy ageing. Of course the lamellar structure is formed by a discontinuous mechanism and is an incoherent equilibrium state as was mentioned above.

These alternating lamellae are able to grow continuously at the expense of the coherent phases formed within the grains. Finally, the grains are converted completely to the alternating lamellar structure.

\section{Two-phase Region of Coexisting AuCull and $\alpha_{2}$ Phases}
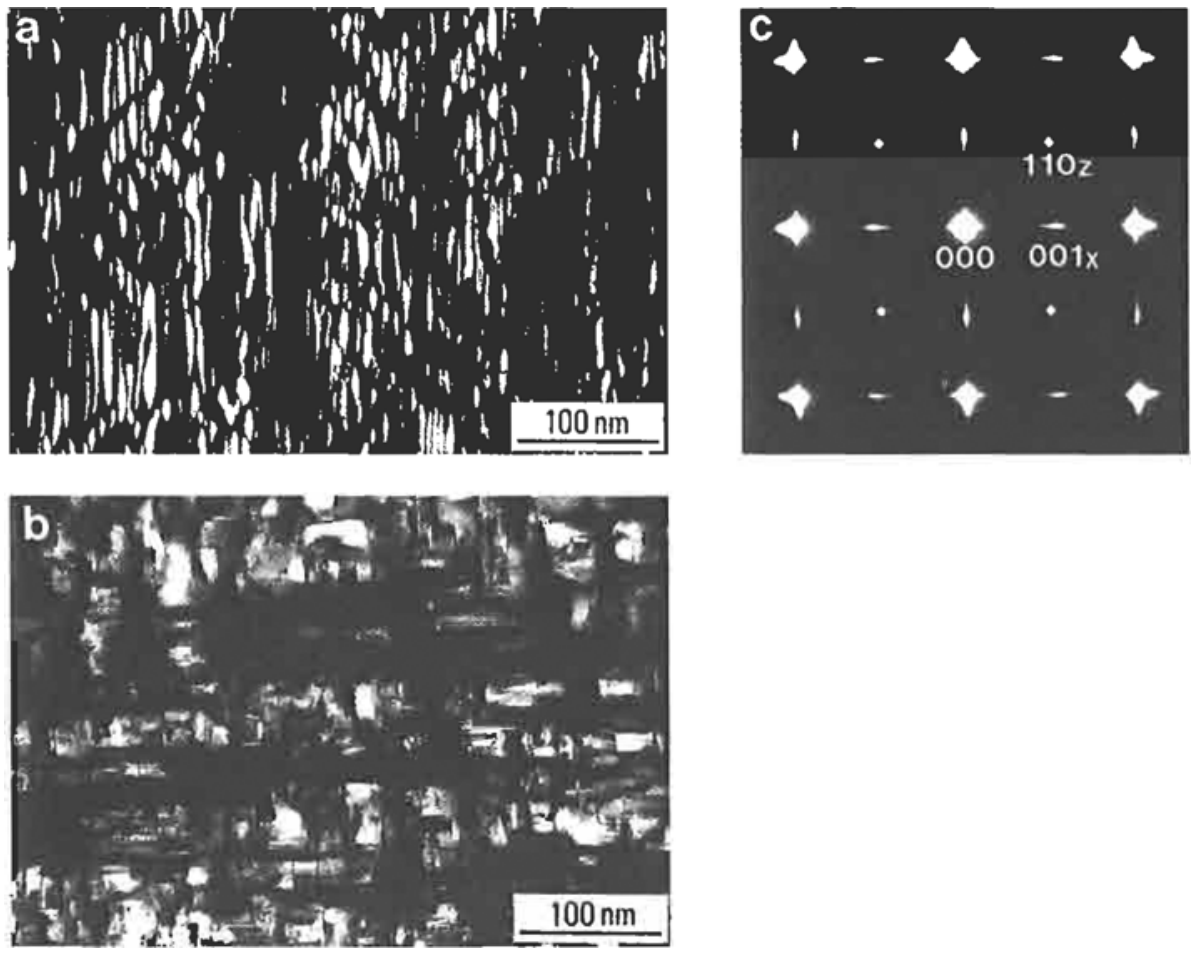

Figure 9

TEM micrographs and SAED pattern for the $19 \mathrm{~K}$ alloy aged at $533 \mathrm{~K}$ for $60 \mathrm{ks;}$ ( $a$ ) and (b) dark-field images produced using the $001 X$ and $110 \mathrm{Z}$ superlattice reflections, respectively, (c) [001] SAED pattern
Figures $\mathbf{8 a}$ and $\mathbf{8 b}$ show dark- field images taken from the $16 \mathrm{~K}$ alloy aged at $613 \mathrm{~K}$ for $10 \mathrm{ks}$ using the $00 \mathrm{l}_{\mathrm{X}}$ and $110_{\mathrm{Z}}$ superlattice reflections; the SAED pattern and its schematic representation corresponding to the above dark-field micrographs are shown in Figures $8 \mathrm{c}$ and $8 \mathrm{~d}$, respectively.

For simplicity, the Miller indices used here relate to the $\mathrm{AuCuI}\left(\mathrm{Ll}_{0}\right)$ tetragonal superlattice. In the SAED pattern or its schematic representation, $h \mathrm{kl}_{\mathrm{X}}$ and $\mathrm{hk} \mathrm{l}_{\mathrm{Z}}$ refer to the $\mathrm{L} \mathrm{l}_{0}$ ordered lattice with the $c$-axis perpendicular to and parallel to the incident electron beam, respectively. It is clear that the 001 and equivalent superlattice reflections split into and 110 types of superlattice reflections and their splitting in the SAED pattern result from the formation of three orientation variants of long period superstructure of Au-CuII phase, as is observed in Figures $8 \mathrm{a}$ and $8 \mathrm{~b}$.

The microstructure shown in Figure $8 \mathrm{a}$ is characterized by a block-like structure, not by thin platelets [8]. Moreover, these blocks of the ordered regions show something like hexagonal or octagonal configurations or their combination which implies occurrence of $\left[\begin{array}{lll}1 & 1 & 0\end{array}\right]$ twinning. The same configuration has been found in the AuCuII ordered phase coexisting with the $\alpha_{1}$ and $\alpha_{2}$ phases. 


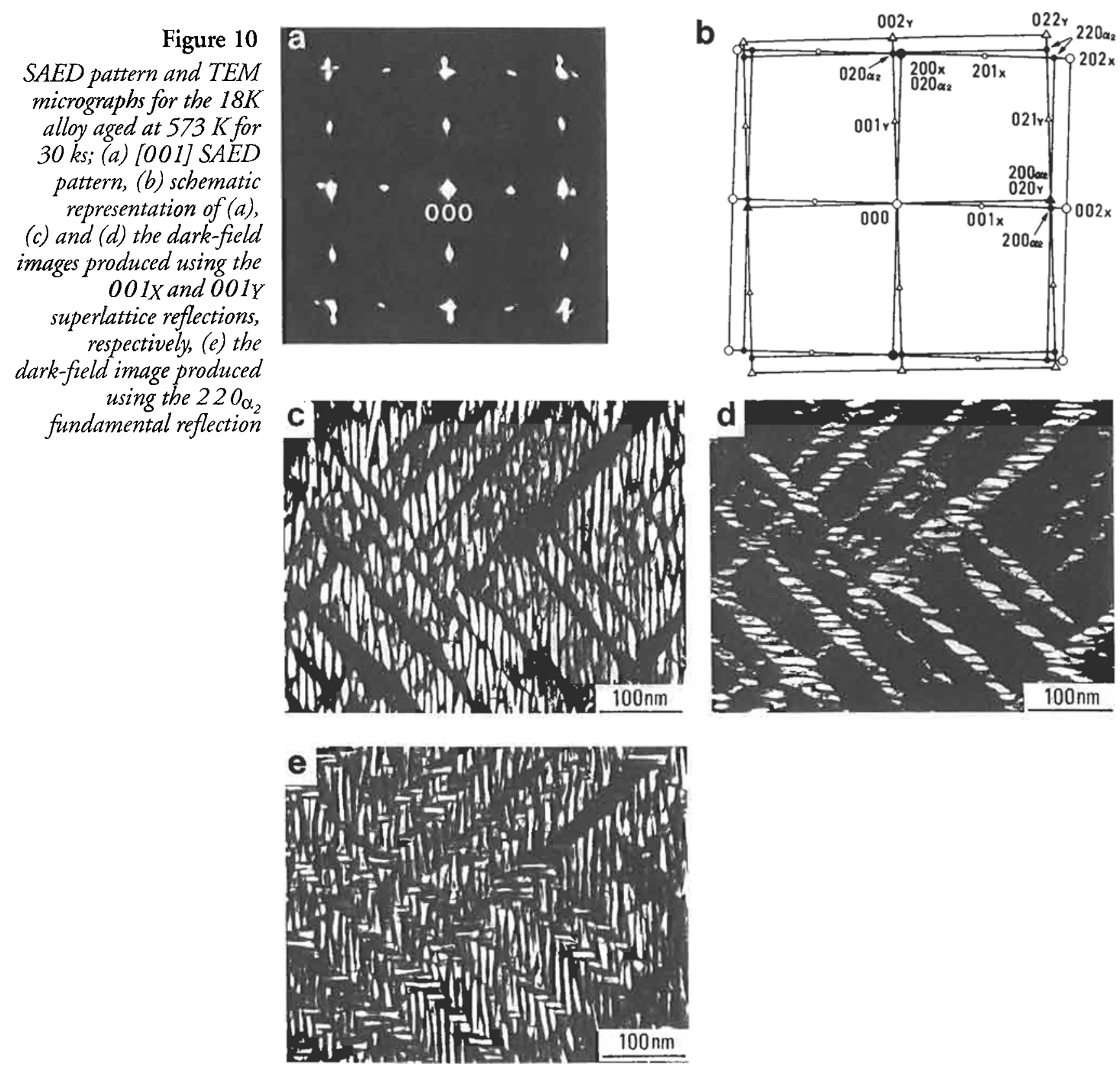

A configuration characteristic of the long period antiphase domain boundary (LPAPB) structure of the $\mathrm{AuCuII}$ phase is clearly visible in the dark-field micrographs shown in Figures $8 \mathrm{a}$ and $8 \mathrm{~b}$. However, the $\alpha_{2}$ phase is indistinguishable from the AuCuII ordered phase in the SAED pattern and the darkfield images because diffraction spots corresponding to the $\alpha_{2}$ phase appear at positions very close to the fundamental spots of the $\mathrm{Z}$-variant of the $\mathrm{AuCuII}$ ordered phase in this temperature range as will be discussed below.

\section{Two-phase Region of Coexisting AuCul and $\alpha_{2}$ Phases}

Figures $9 \mathrm{a}$ and $9 \mathrm{~b}$ show dark-field images of the $19 \mathrm{~K}$ alloy aged at $533 \mathrm{~K}$ for $60 \mathrm{ks}$ using the $001_{X}$ and $110_{Z}$ superlattice reflections, respectively. The SAED pattern shown in Figure 9c exhibits the simultaneous presence of the $001_{X}, 110_{Z}$ and equivalent superlattice reflections.

This indicates the formation of three orientation variants of $\mathrm{AuCuI}$ ordered platelets on the matrix 
$\{100\}$ planes as was observed previously in the $18 \mathrm{~K}$ gold alloy [9], commercial dental gold alloy containing platinum [10] or palladium [11,12]. The $\alpha_{2}$ phase is indistinguishable from the Au-CuI ordered phase in the SAED pattern for the reason mentioned above. If we can obtain an SAED pattern which does not include the $110_{Z}$ and equivalent superlattice reflections, i.e. contains merely the $\mathrm{X}$ - and $\mathrm{Y}$-variants of $\mathrm{AuCuI}$ ordered platelets, the diffraction spots corresponding to the $\alpha_{2}$ phase can be distinguished from the 200,220 and equivalent fundamental reflections in the Z-variant of AuCuI ordered platelets, because they never superimpose on each other due to a slight difference in the lattice spacings.

Figures $10 \mathrm{a}$ and $10 \mathrm{~b}$ show an SAED pattern and its schematic representation for the $18 \mathrm{~K}$ alloy aged at $573 \mathrm{~K}$ for $30 \mathrm{ks}$. The absence of the 110 and equivalent superlattice reflections in the SAED pattern indicates that only two out of three orientation variants of AuCuI platelets are formed in this alloy; the formation of the $\mathrm{Z}$-variant of $\mathrm{AuCuI}$ ordered platelets is suppressed in the present case. Diffraction reflections corresponding to the $\alpha_{2}$ phase which are designated $200_{\alpha_{2}}, 020_{\alpha_{2}}$ and $22 \mathrm{\alpha}_{2}$ are distinguishable with certainty from the fundamental reflections for the AuCuI ordered phase due to the absence of the diffraction reflections arising from the Z-variant of the AuCuI ordered phase as seen in Figures 10a and $10 \mathrm{~b}$.

Dark-field images produced using the $001_{X}$ and $00 I_{Y}$ superlattice reflections are given in Figures $10 \mathrm{c}$ and $10 \mathrm{~d}$, respectively. Figure $10 \mathrm{e}$ shows the dark-field image formed by using the $220_{\alpha_{2}}$ fundamental reflection.

These microstructures suggest that alternating thin lamellae are arranged in a stepwise fashion composed of Au$\mathrm{CuI}$ ordered platelets and the $\alpha_{2}$ phase which are formed alternately on the $\{100\}$ planes.
The configuration of the splitting in the diffraction spots in Figure 10a indicates that twinned lamellae are formed to relieve strains induced by tetragonal distortion.

\section{Three-phase Region of Coexisting AuCul, AuCull and $\alpha_{2}$ Phases}

Figures $11 \mathrm{a}$ and $11 \mathrm{~b}$ are dark-field images of the $16 \mathrm{~K}$ alloy aged at $563 \mathrm{~K}$ for $30 \mathrm{ks}$ produced by using the $001_{X}$ and $110_{Z}$ superlattice reflections, respectively. An SAED pattern and its schematic representation are shown in Figures $11 \mathrm{c}$ and $11 \mathrm{~d}$. In the SAED pattern, there are found only two orientation variants of the superlattice reflections, i.e. $001 \mathrm{X}$ and $110 \mathrm{Z}$; the $\mathrm{Y}$ variant of the superlattice reflection, $001 \mathrm{Y}$, is not found. Moreover, it is clear that these superlattice reflections consist of those from $\mathrm{AuCuI}$ and $\mathrm{AuCuII}$ ordered phases in the SAED pattern.
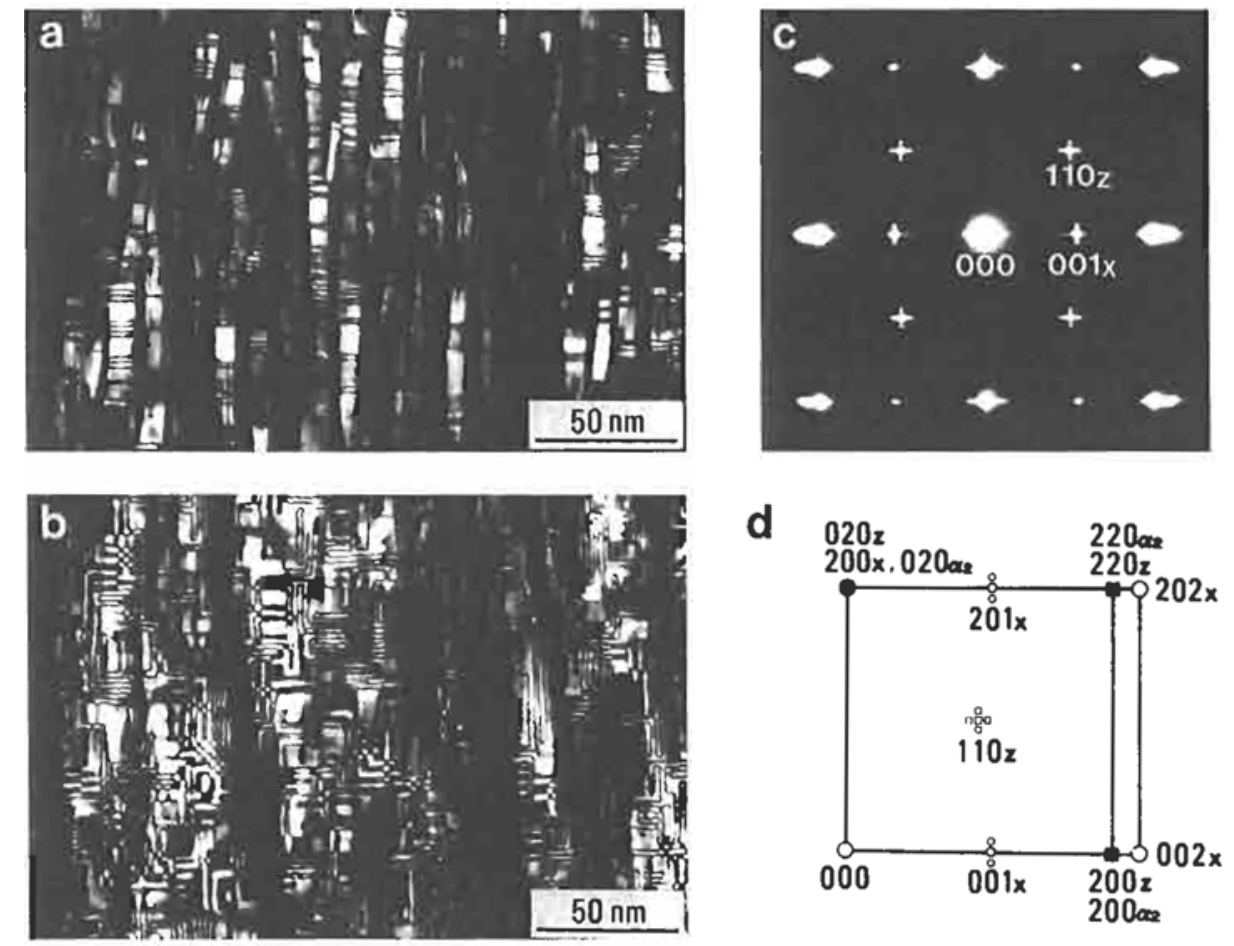

Figure 11

TEM micrographs and SAED pattern for the $16 \mathrm{~K}$ alloy aged at $563 \mathrm{~K}$ for $30 \mathrm{ks}$; (a) and (b) dark-field images produced using the $001 X$ and $110 Z$ superlattice reflections, respectively, (c) [001] SAED pattern, (d) schematic representation of $(c)$ 
The dark-field images are produced by including the splitting of the superlattice reflections in the aperture; therefore, we can observe two regions which are distinguished by their contrast, i.e. a well developed LPAPB structure attributed to the AuCull ordered superlattice reflections is not clearly visible in the SAED pattern, the dark-field image which is produced using the 110 superlattice reflection represents the characteristics of the LPAPB structure in the narrow regions as is indicated by the arrow in Figure $12 \mathrm{~b}$.
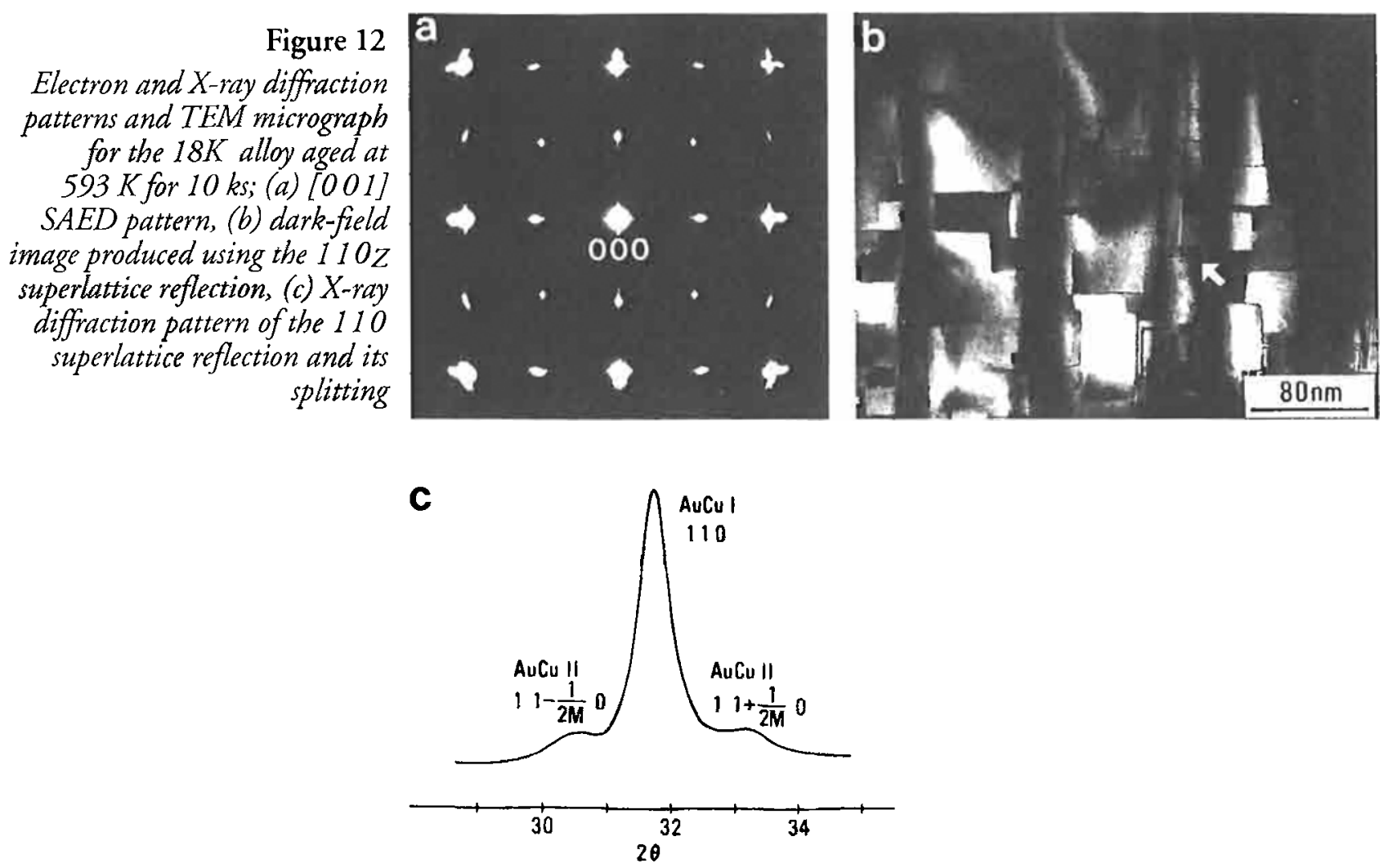

phase and an area of plain bright contrast arising from the AuCuI ordered phase. The $\alpha_{2}$ phase cannot be distinguished from the $\mathrm{AuCuI}$ and $\mathrm{AuCuI}$ ordered phases because the diffraction reflections arising from the $\alpha_{2}$ phase are superimposed on the positions of the fundamental reflections corresponding to the Z-variant of the $\mathrm{AuCuI}$ and $\mathrm{AuCuII}$ ordered phases. From careful inspection of the dark-field images, it is clear that the dark regions observed in Figure 11a are neither the $\mathrm{Y}$-variant of $\mathrm{AuCuI}$ and $\mathrm{AuCu}$ II ordered phases nor the $\mathrm{Z}$-variant of these ordered phases. Moreover, the ordered phases are not formed in the present case. Thus, it is thought that the dark regions must correspond to the $\alpha_{2}$ phase.

A three-phase coexisting region is also observed in the $18 \mathrm{~K}$ alloy aged at $593 \mathrm{~K}$ for $10 \mathrm{ks}$, as seen in Figure 12a. Although the cross-like splitting of the 110
This feature is also supported by the 110 superlattice reflection in the $\mathrm{X}$-ray diffraction profile for the $18 \mathrm{~K}$ alloy aged at $593 \mathrm{~K}$ for $10 \mathrm{ks}$, as seen in Figure $12 \mathrm{c}$. The diffraction reflections arising from the $\alpha_{2}$ phase are not visible in Figure 12a because the fundamental reflections of the $\mathrm{Z}$-variant $\mathrm{AuCuI}$ and $\mathrm{AuCuII}$ ordered phases overlap the positions for the $\alpha_{2}$ phase.

\section{Three-phase Region of Coexisting AuCull, $a_{1}$ and $\alpha_{2}$ Phases}

An SAED pattern taken from the $16 \mathrm{~K}$ alloy aged at 633 $\mathrm{K}$ for $300 \mathrm{ks}$ is shown in Figure 13a. A schematic representation of the SAED pattern is given in Fig- 
ure $13 \mathrm{~b}$, which includes fec fundamental reflections up to 440 to indicate the separation of diffraction spors attributed to each phase generated by ageing. It is to be noted that there are reflections of $440_{\alpha}$ and $440_{\alpha_{2}}$ in addition to those of $440 \mathrm{X}, 044_{\mathrm{Y}}$ and $440_{\mathrm{Z}}$. Furthermore, superlattice reflections of the $001_{X}, 001_{Y}$ and $110_{Z}$ types are observed in the SAED pattern. It is, therefore, concluded that the SAED pattern reveals the coexistence of the three orientation variants of the AuCuII ordered phase and the $\alpha_{1}$ and $\alpha_{2}$ fcc phases at this temperature. LPAPB structure is observed clearly in the dark-field images shown in Figures $13 \mathrm{c}$ and $13 \mathrm{~d}$ which are produced using the $001 \mathrm{X}$ and $110_{\mathrm{Z}}$ superlattice reflections, respectively.

Thus, a region with three coexisting phases, i.e. the $\alpha_{1}$ and $\alpha_{2}$ disordered fcc phases and the AuCull ordered phase, is identified within a narrow temperature range as seen in the coherent phase diagram (Fig. 3). There is found the hexagonal configuration of the ordered regions in the dark-field image shown in Figure $13 \mathrm{c}$ which is a configuration similar to that shown in Figure 8a. This hexagon of the ordered regions is surrounded by the $\{100\}$ and $\{110\}$ planes.
The AuCull ordered phase which has a block-like shape is formed on the $\{100\}$ matrix planes. In Figure 13c, only the $\{110\}$ twin planes are found, since only the ordered regions which have AuCuII c-axis alternation in the sequence $X Y X Y$... out of the sequences YZYZ... and ZXZX... are visible. Thus, it can be deduced that the hexagonal configurations of the AuCuIl ordered region are formed due to the occurrence of twinning to accommodate the tetragonal strain induced during ordering.

\section{Three-phase Region of Coexisting $\mathrm{Cu}_{3} \mathrm{Au}$, AuCull and $\alpha_{2}$ Phases}

This three-phase region is found in a narrow composition range between the region of coexistence of $\mathrm{Cu}_{3} \mathrm{Au}$ and $\alpha_{2}$ and the region of coexistence of AuCuII and $\alpha_{2}$ phases at a temperature below the ternary eu-tectoid isotherm, as seen in Figure 3.

Dark-field images of the $14 \mathrm{~K}$ alloy aged at $533 \mathrm{~K}$ for $60 \mathrm{ks}$ are shown in Figures 14a and 14b, obtained
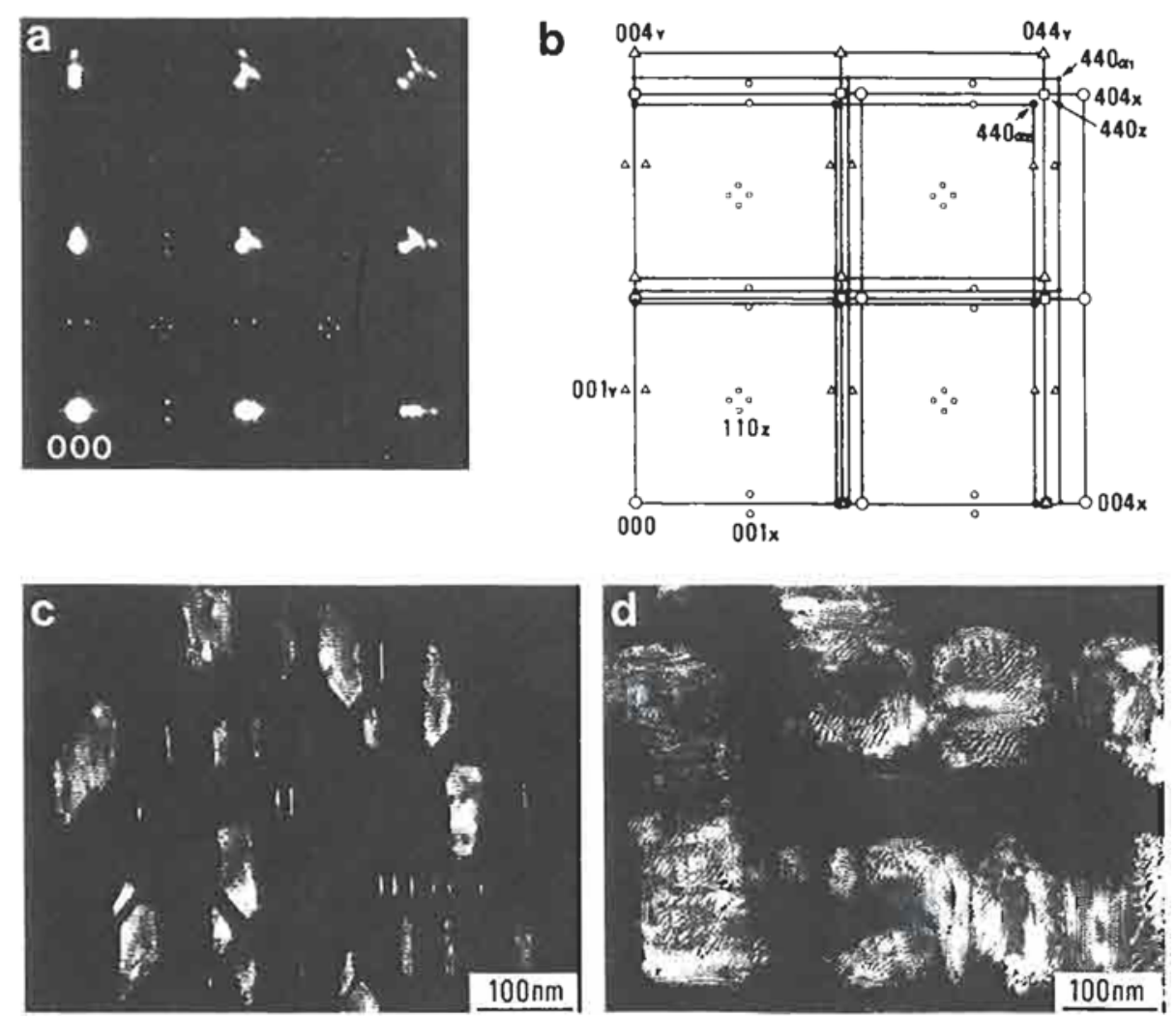

Figure 13

SAED pattern and TEM micrographs for the $16 \mathrm{~K}$ alloy aged at $633 \mathrm{~K}$ for $300 \mathrm{ks}$; (a) 5001$]$ SAED pattern, (b) schematic representation of (a), (c) and (d) dark-field images produced using the $001 X$ and $110 Z$ superlattice reflections, respectively 
Figure 14

TEM micrographs and SAED pattern for the $14 \mathrm{~K}$ alloy aged at $533 \mathrm{~K}$ for $60 \mathrm{ks} ;($ a) dark-field image produced using the $001 X$ of $A u C u I I$ and the

$\mathrm{Cu} 3$ Au superlattice reflections,

(b) dark-field image produced using the

$110 Z$ of $A u C u$ II and the 110 of Cu3Au superlatice reflections, (c) [OO I] SAED pattern, (d) schematic
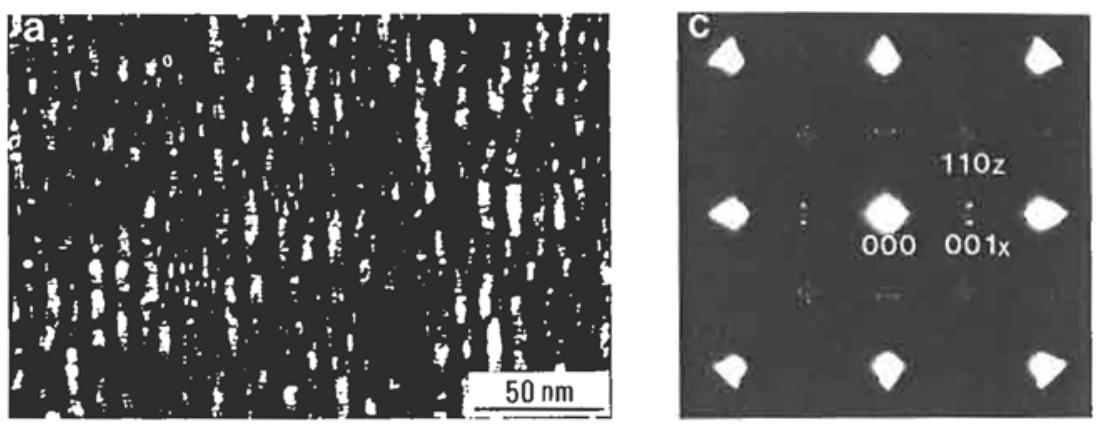
representation of $(c)$
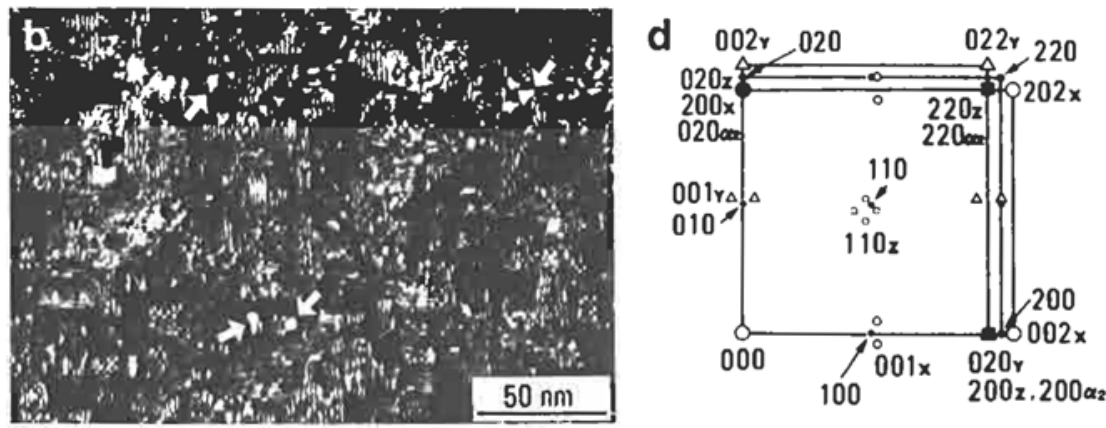

using the $001 \times$ superlattice reflection of $\mathrm{AuCuII}$ (including the 100 superlattice reflection corresponding to $\mathrm{Cu}_{3} \mathrm{Au}$ ) and the $110_{\mathrm{Z}}$ of $\mathrm{AuCuII}$ (including the 110 of $\mathrm{Cu}_{3} \mathrm{Au}$ ), the pairs of reflections being located very close to one another as seen in the SAED pattern and its schematic representation in Figures $14 \mathrm{c}$ and $14 \mathrm{~d}$. In the SAED pattern, the three orientation variants of $\mathrm{AuCuII}$ ordered platelers,
$\mathrm{Cu}_{3} \mathrm{Au}$ ordered phase and $\alpha_{2}$ phase are visible, although the diffraction reflections attributed to the $\alpha_{2}$ phase cannot be distinguished from the fundamental reflections of the Z-variant of the AuCuII ordered phase. In Figure 14b, two types of ordered regions are identified by their contrast, since $\mathrm{Au}$ CuIl contains LPAPB structure and $\mathrm{Cu}_{3} \mathrm{Au}$ shows a plain contrast, indicated by the arrows.
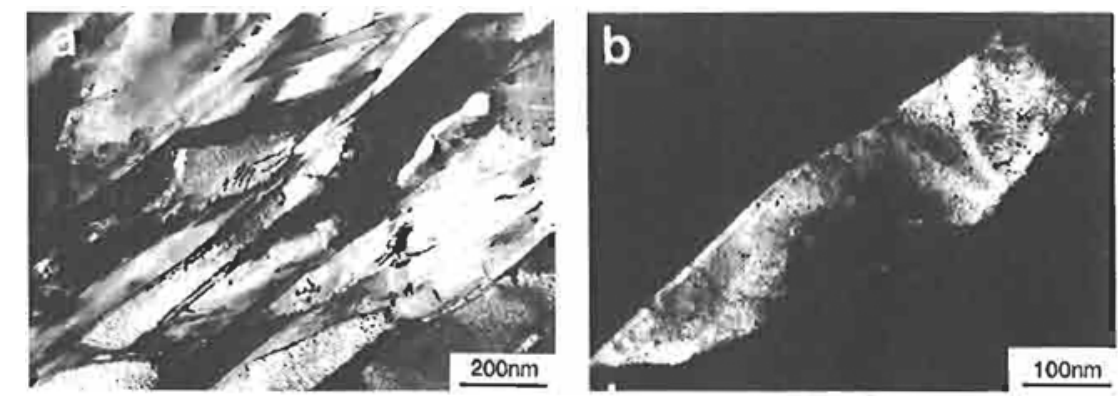

Figure 15

TEM micrographs and SAED pattern for the $16 \mathrm{~K}$ alloy aged at $613 \mathrm{~K}$ for $100 \mathrm{ks;}$ (a) a bright-field image,

(b) dark-field image produced using the $110 Z$ superlattice reflection, (c) [O0 1] SAED pattern of (a) and (b)

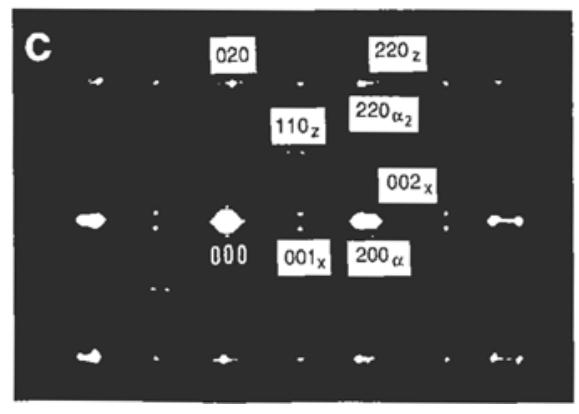




\section{Three-phase Region of Coexisting $\mathrm{Cu}_{3} \mathrm{Au}, \alpha_{1}$ and $\alpha_{2}$}

Because this three-phase region was assumed to lie in a narrow composition range between the region of coexisting $\mathrm{Cu}_{3} \mathrm{Au}$ ordered phases, $\alpha_{2}$ disordered phases and the $\alpha_{1}, \alpha_{2}$ disordered phases, no evidence could be obtained experimentally. Therefore, the phase boundaries are merely deduced from the theoretical coherent phase diagram shown in Figure 4. electrochemical stability, i.e. corrosion or tarnishing, of the alloys. Therefore, microstructures of several incoherent phases will be described in this section.

Figures 15a and 15b show bright-field and darkfield images of the $16 \mathrm{~K}$ alloy aged at $613 \mathrm{~K}$ for $100 \mathrm{ks}$. Coarse alternating lamellae which have smooth interfaces and no strain contrast are observed to proceed into the grains from the grain boundaries. The SAED pattern which is given in Figure $15 \mathrm{c}$ shows that these lamellae are composed of the $\alpha_{2}$ disordered and AuCuII
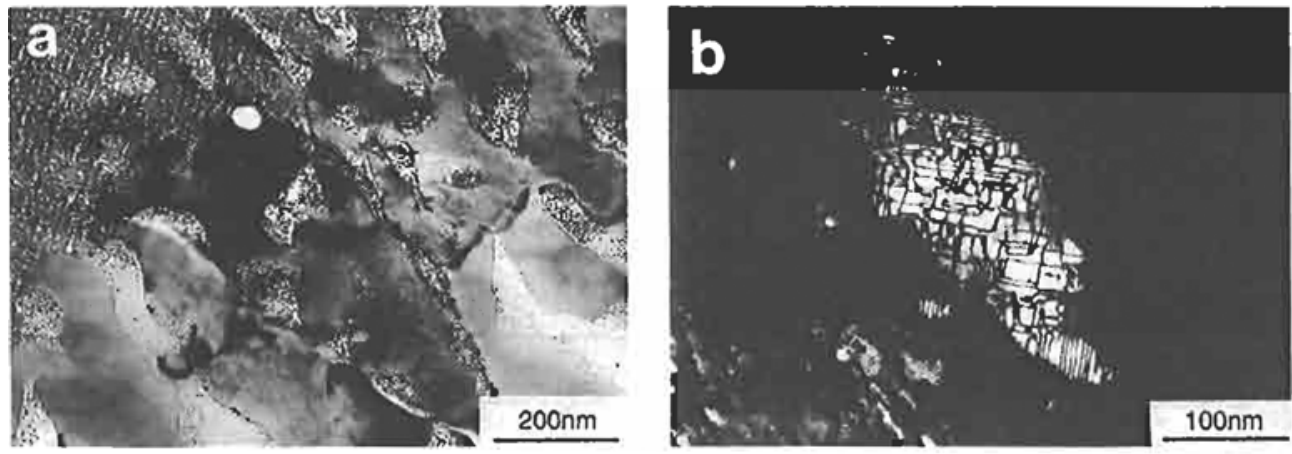

Figure 16

TEM micrographs and $S A E D$ pattern for the $12 \mathrm{~K}$ alloy aged at $633 \mathrm{~K}$ for $30 \mathrm{ks}$; (a) a brightfield image, (b) dark-field image produced using the 110 superlattice reflection, (c) [001] SAED pattern

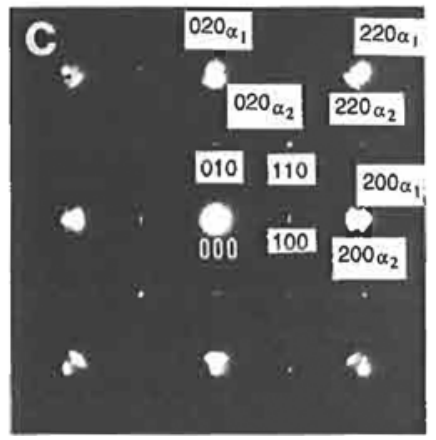

\section{Microstructures Formed by Incoherent Phases}

During the course of a systematic TEM examination to determine the coherent phase diagram of the $\mathrm{Au}_{\mathrm{x}}$ $\left(\mathrm{Ag}_{0.24} \mathrm{Cu}_{0.76}\right)_{1-\mathrm{x}}$ section in the Au-Cu-Ag ternary system, grain boundary products were observed in several cases. According to the hypothesis of Allen and Cahn [3], the grain boundary products are thought to be incoherent phases. When we inquire into age-hardening mechanisms in dental gold alloys as well as jewellery gold alloys, the incoherent phases have also to be taken into consideration, because they have an undesirable effect not only on mechanical properties but also on ordered phases. It is thought that the AuCuII ordered phase is converted from the $\alpha_{1}$ copper-rich phase. A typical LPAPB structure of AuCuII ordered phase is visible in the dark-field image produced using the $110_{Z}$ superlattice reflection. These lamellae are able to grow continuously at the expense of the coherent AuCuII ordered phase formed within grains with lengthy ageing, as was observed in several commercial dental gold alloys [12]. The LPAPB structure formed within grain boundary products was also found in the $12 \mathrm{~K}$ alloy on ageing in the temperature range between 623 and $633 \mathrm{~K}$ [13].

The grain boundary product which is constructed of alternating lamellae is observed in a bright-field 

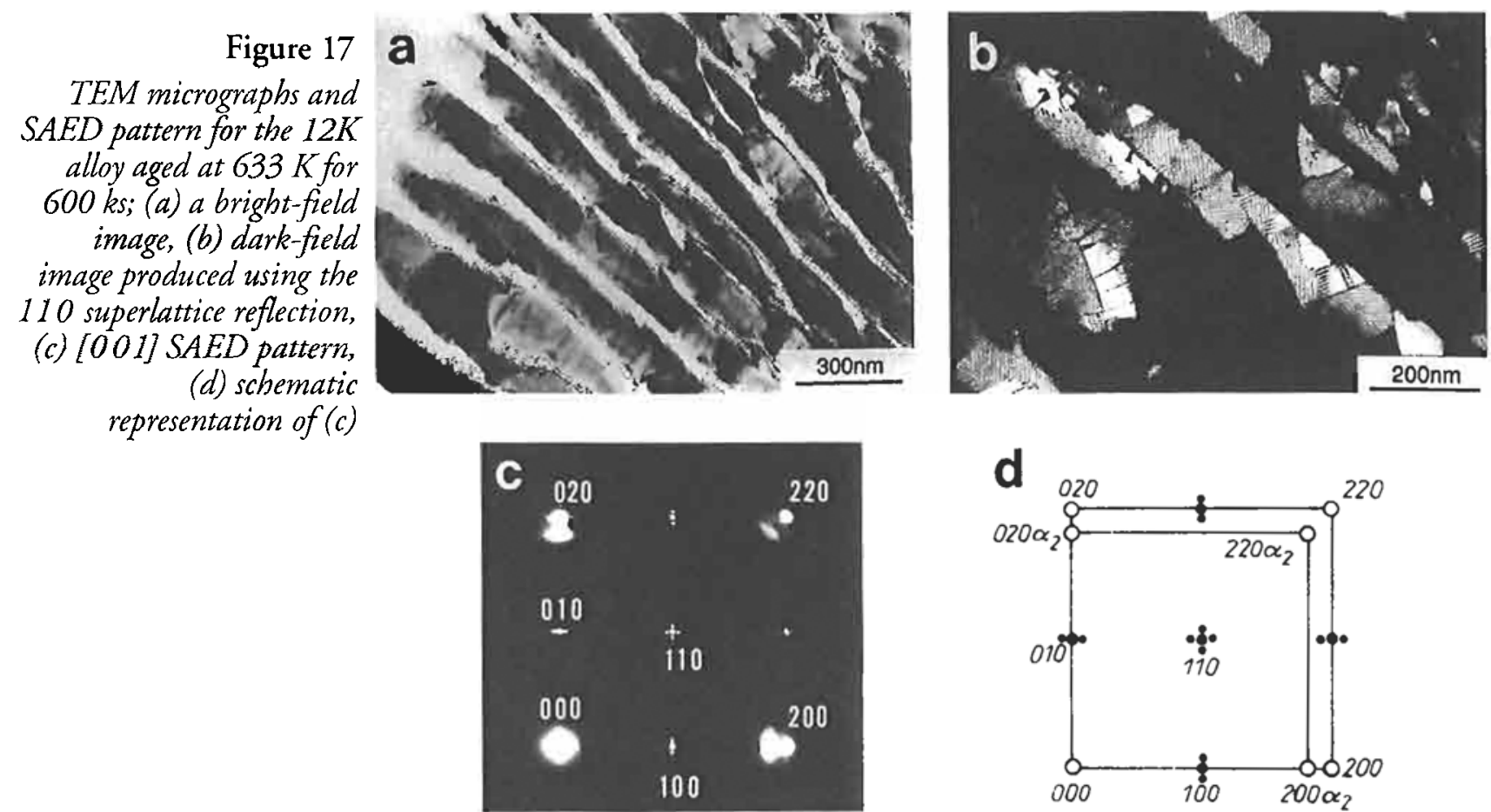

micrograph of the $12 \mathrm{~K}$ alloy aged at $633 \mathrm{~K}$ for $30 \mathrm{ks}$ as seen in Figure 16a. The dark-field image produced using the 110 superlattice reflection and the corresponding SAED pattern are shown in Figures $16 \mathrm{~b}$ and $16 \mathrm{c}$, respectively. An arrangement of black stripes lined up in two mutually perpendicular directions, i.e. $<100>$ directions, is found in Figure 16b.

Such configurations are thought to be antiphase domain boundaries. In the dark field image, the configurations of the central part and the peripheral region of the lamellae are somewhat different. The former exhibits a labyrinth-like configuration, while the latter is a parallel arrangement of the antiphase domain boundary although the labyrinth-like pattern still remains in this region.

As is deduced from the SAED pattern, the grain boundary product consists of the $\alpha_{1}$ and $\alpha_{2}$ phases, both $\mathrm{fcc}$ in structure and with lattice parameters $0.378 \mathrm{~nm}$ and $0.408 \mathrm{~nm}$, respectively. Superlatrice reflections are seen at the 100,110 and equivalent positions of the $\alpha_{1}$ phase, which is a copper-rich phase. Furthermore, it can be seen that the 100 and 110 type superlattice reflections are elongated in orthogonal directions, even if they are accompanied by diffuse scattering. From the above observation, it is thought that the labyrinth-like configuration corresponds to the $\mathrm{Cu}_{3} \mathrm{AuI}$ or $\mathrm{Z}$-variant of $\mathrm{Cu}_{3} \mathrm{AuI}$; however, they cannot be distinguished from one another at this stage of ageing, and the parallel arrangement of the antiphase domain boundary represents the $\mathrm{X}$ - and $\mathrm{Y}$-variants of the $\mathrm{Cu}_{3} \mathrm{AuII}$ ordered phase. This siruation is explained by considering a model of the reciprocal lattice which is constructed from three orientation variants of the $\mathrm{Cu}_{3}$-AuII long period superlattice, i.e. directions perpendicular to periodicity, according to Marcinkowsky and Zwell [14].

Much reliable evidence for the above can be seen in Figure 17 which is obtained from the $12 \mathrm{~K}$ alloy aged at $633 \mathrm{~K}$ for $600 \mathrm{ks}$. The bright-field image shown in Figure 17a represents a well-oriented lamellar structure of the grain boundary product. Figure $17 \mathrm{~b}$ shows the dark-field image produced by using the 110 superlattice reflection including the associated satellite reflections

An SAED pattern and its schematic representation are given in Figures $17 \mathrm{c}$ and $17 \mathrm{~d}$, respectively. In the dark-field image, we can observe that sets of parallel fringes abut on one another at right angles and that in another region there are no periodic fringes. The plain contrast regions are thought to be $\mathrm{Cu}_{3} \mathrm{AuI}$ ordered regions. It should be noted that the spacings of the periodic fringes are almost equal, different 
from the labyrinth-like configuration. It seems that the $\mathrm{Cu}_{3} \mathrm{AuI}$ ordered regions are eaten away by the LPAPB structure.

The formation of LPAPB structure of ordered phase will be explained rationally by taking into consideration a coherent and an incoherent phase diagram. In the $12 \mathrm{~K}$ alloy, $\mathrm{X}$-ray and TEM studies have revealed the following process of phase transformation during isothermal ageing at $633 \mathrm{~K}[7,13]$ :

(1) appearance of the modulated structure resulting from spinodal decomposition in the early stage, occurrence of $\mathrm{Cu}_{3} \mathrm{Au}$ ordering from the copperrich $\alpha_{1}^{\prime}$ metastable phase after generation of phase separation within a grain by a continuous mechanism, and then

(2) formation of a lamellar structure consisting of the $\alpha_{1}$ and $\alpha_{2}$ stable phase at the grain boundary by a discontinuous mechanism.

The process (1) takes place prior to the process (2) during isothermal ageing.

According to Allen and Cahn [3], coherent phases must be metastable and, in the presence of an incoherent phase, unstable. Therefore, it can be supposed that the process (1) corresponds to the coherent phase change and the process (2) to the incoherent phase change, because the coherent phases, i.e. $\alpha_{1}^{\prime}, \alpha_{2}^{\prime}$ disordered phases and the $\mathrm{Cu}_{3} \mathrm{Au}$ ' ordered phase formed within the grain, are indeed metastable, but are unstable in the presence of the grain boundary product which consists of the $\alpha_{1}, \alpha_{2}$ disordered and $\mathrm{Cu}_{3}$ - $\mathrm{Au}$ II ordered incoherent phases.

Figure 18a represents a plausible phase diagram of the $\mathrm{Au}-\mathrm{Cu}-\mathrm{Ag}$ isothermal section at $633 \mathrm{~K}$ obtained by superimposing the experimental data [4] on the theoretical phase diagram [15], although some modification has been made on the phase diagram. Figure 18b exhibits an enlargement of a portion of Figure $18 \mathrm{a}$ for greater detail.

In the diagram, the solid and dashed lines correspond to the coherent and incoherent isothermal sections, respectively, as well as the three-phase triangles. Although the spinodal locus is not shown in Figure 18a, the first phase change, i.e. the process (1), is the formation of the modulated structure resulting from the spinodal decomposition; the $\alpha_{2}^{\prime}$ and $\mathrm{Cu}_{3} \mathrm{Au}$ phases are formed subsequently by phase separation, as is observed in Figure 4. From Figure 18b, it can

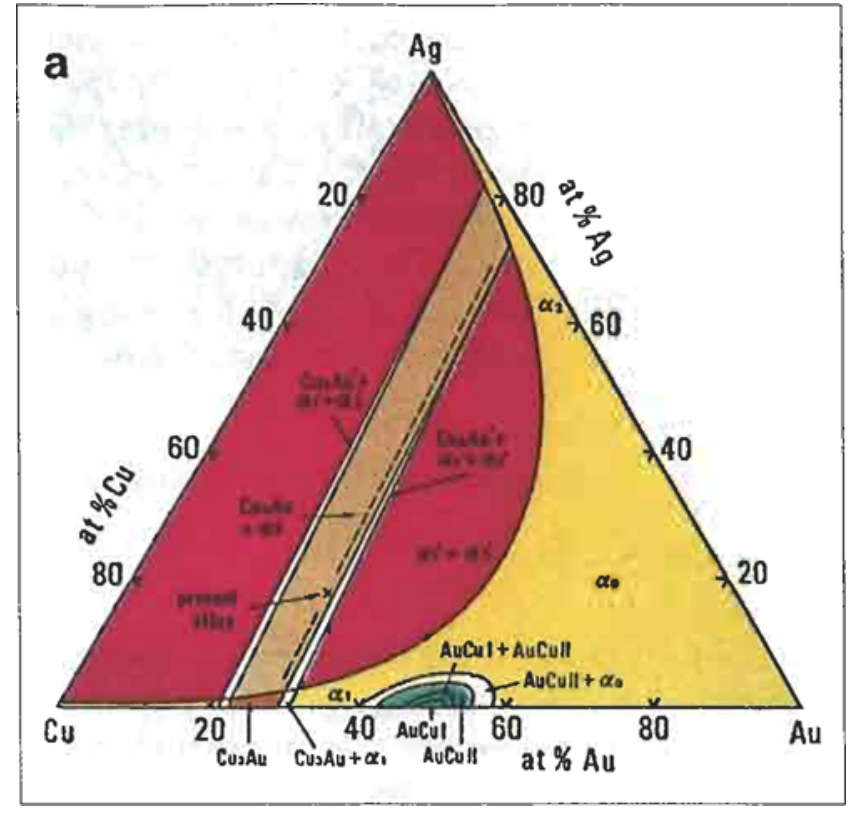

Figure 18

A plausible phase diagram of the Au-Cu-Ag ternary system; (a) $633 \mathrm{~K}$ isothermal section of the coherent phase diagram (solid line) and the incoherent phase diagram (dashed line), (b) enlargement of a part of (a)

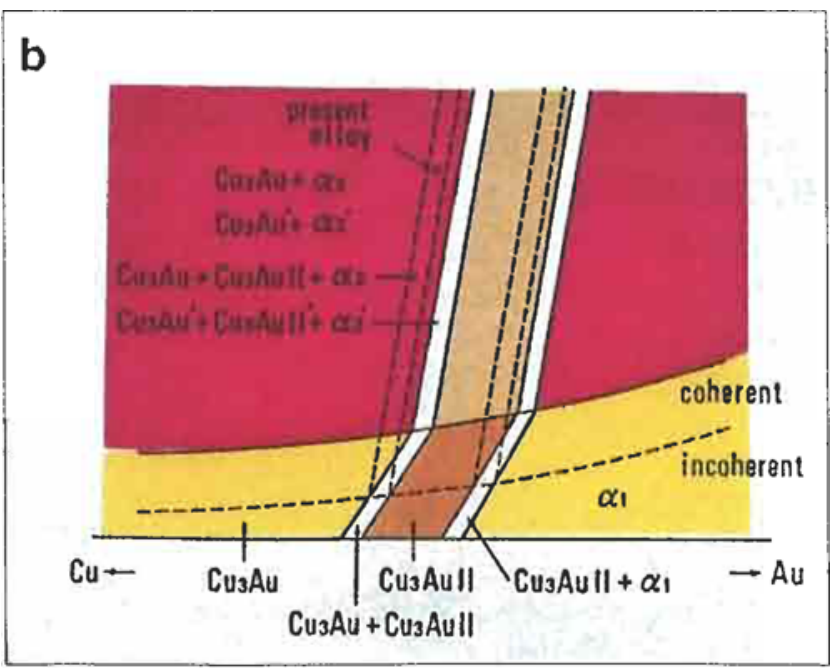

be seen that these changes are generated on the tieline depicted within the coherent phase diagram which contains the metastable $\alpha_{2}^{\prime}$ and $\mathrm{Cu}_{3} A u^{\prime}$ phases, and cannot run on due to the occurrence of the subsequent phase change, i.e. the process (2). When the process (2) is induced prior to the accomplishment of the process (1), the tie-line is located well inside a 
narrow margin with the incoherent three-phase triangle which contains the stable $\alpha_{2}, \mathrm{Cu}_{3} \mathrm{AuI}$ and LPAPB structure of $\mathrm{Cu}_{3} \mathrm{AuII}$ phases, as seen in Figure 18b. The observations indicate that the lamellar structure formed at grain boundaries consists of the $\alpha_{2}, \mathrm{Cu}_{3}$ $\mathrm{AuI}$ and $\mathrm{Cu}_{3} \mathrm{AuII}$ phases. Thus, it is rational to suppose that the LPAPB structure of $\mathrm{Cu}_{3}$-AuII is only generated in the lamellar structure at the grain boundary.

\section{CONCLUSIONS}

To achieve control of the mechanical properties such as strength, ductility, fracture toughness, and chemical stability in dental gold alloys, it is most important to understand the correlation between microstructural morphology and phase transformation. A coherent phase diagram gives us effective information concerning phase transformations and related microstructural features for a given alloy.

This review article shows that a coherent phase diagram of the $\mathrm{Au}_{\mathrm{x}}-\left(\mathrm{Ag}_{0.24} \mathrm{Cu}_{0.76}\right)_{1-\mathrm{x}}$ section in the
Au-Cu-Ag ternary system may be constructed on the basis of TEM observations of microstructural configurations and SAED analysis of crystal structures induced by phase transformations. The work described was based on results obtained mainly from the Department of Dental Materials Science, Nagasaki University School of Dentistry. The coherent phase diagrams of other vertical sections in the Au-Cu-Ag ternary system are to be published elsewhere by the present authors in the near future.

\section{ACKNOWLEDGEMENTS}

The authors would like to thank the Japanese Ministry of Education, Science and Culture for its financial support by Grant-in-Aid for Scientific Research (62570880, 01460241) and Grant under the Monbusho International Scientific Research Program, Joint-Research (63044111, 01044112).

\section{REFERENCES}

1. K. Yasuda and M. Ohta, 'Age-hardening in a 14 carat dental gold alloy', Proc. 3rd. Int. Precious Met. Conf., Chicago, IL., IPMI., 1979, 137-64.

2. K. Yasuda and M. Ohta, J. Dent. Res., 1982, 61, 473-79.

3. S. M. Allen and J.W. Cahn, Acta Metall., 1975, 23, 1017-26.

4. M. Nakagawa and K. Yasuda, J. Less-Comm. Met., $1988,138,95-106$.

5. H. Yamauchi, H.A. Yoshimatsu, A.R. Forouhi and $\mathrm{D}$. de Fontaine, 'Phase relation in $\mathrm{Cu}-\mathrm{Ag}$-Au ternary alloys', R.O. McGachie and A.G. Brandley Eds. Precious Metals, Pergamon, Toronto, 1980, 241-49.

6. R. Kikuchi, J.M. Sanchez, D. de Fontaine and H. Yamauchi, Acta Metall., 28 1980, 651-662.

7. M. Nakagawa and K. Yasuda, J. Mater. Sci, 1988, 23, 2975-82.

8. K. Hisatsune, K-I. Udoh, B.I. Sosrosoedirjo, T. Tani and K. Yasuda, J. Alloys Comp.,1991, 176, 269-83.

9. Y. Kanzawa, K. Yasuda and H. Metahi, J. Less-Comm. Met., 1975, 43, 121-28.

10. K. Yasuda and M. Ohta, J. Less-Comm. Met., 1980, 70, 75-87.

11. K. Yasuda, K. Udoh, K. Hisatsune and M. Ohta, Dent. Mater. J., 1983, 2, 48-58.

12. K-I. Udoh, K. Hisatsune, K. Yasuda and M. Ohta, Dent. Mater. J., 1984, 3, 253-61.

13. M. Nakagawa and K. Yasuda, Phys. stat. sol. (a), $1988,107,709-17$.

14. M.J. Marcinkowsky and L. Zwell, Acta Metall., 1963 , 11, 373-90.

15. A. Prince, G.V. Raynor and D.S. Evans, Phase Diagrams of Ternary Gold Alloys, Inst. Metals, London, 1990, 7-42. 